\title{
Effect of an Inhibitor of DNA Methylation on T Cells. II. 5-azacytidine Induces Self-Reactivity in Antigen-Specific $\mathrm{T}^{+}{ }^{+}$Cells
}

\author{
Bruce Richardson
}

ABSTRACT: During T-cell maturation, thymocytes interact with thymic stromal major bistocompatibility complex $(\mathrm{MHC})$ determinants and thymic bormones, and proliferate, apparently in response to $M H C$ gene products, in the absence of antigen. The maturing thymocytes also express a series of cell surface molecules, at one stage coexpressing T4, T6, and T8. Mature $T$ cells express either $T 4$ or $T 8$, lack T6, bear the T3-Ti receptor complex on the cell surface, and require antigen in addition to MHC determinants to proliferate. To study whether DNA methylation may be involved in regulating phenotypic and functional changes observed during thymocyte maturation, cloned, $\mathrm{T4}^{+}$Interleukin-2 dependent, antigen-specific $\mathrm{T}$ cells were treated with an inbibitor of DNA metbylation, 5-azacytidine (5-azaC). The 5-azaC treated cells lost the requirement for antigen and could be activated by autologous macrophages alone. Anti-class II and anti-T3, but not anti-class I monoclonal antibodies, inhibited activation of 5-azaC treated $\mathrm{T4}^{+}$cells by macrophages, implying that the T3-Ti receptorcomplex may be recognizing class $I I M H C$ molecules without antigen. No changes in T3 and T4 expression were noted, and neither T8 nor T6 was induced.

ABBREVIATIONS

\begin{tabular}{|c|c|c|c|}
\hline IL-2 & Interleukin-2 & $\mathrm{HU}$ & hydroxyurea \\
\hline 5-azaC & 5-azacytidine & FITC & fluorescein isothiocyanate \\
\hline $\mathrm{MHC}$ & $\begin{array}{l}\text { major histocompatibility } \\
\text { complex }\end{array}$ & $\begin{array}{l}\mathrm{PE} \\
\mathrm{M} \emptyset\end{array}$ & $\begin{array}{l}\text { phycoerythrin } \\
\text { macrophage }\end{array}$ \\
\hline $\mathrm{d}^{\mathrm{m}} \mathrm{CpdG}$ & $\begin{array}{l}\text { 5-methyldeoxycytidyldeoxy- } \\
\text { guanosine }\end{array}$ & AMLR & $\begin{array}{l}\text { autologous mixed lympho- } \\
\text { cyte reaction }\end{array}$ \\
\hline PBMC & $\begin{array}{l}\text { peripheral blood mononu- } \\
\text { clear cells }\end{array}$ & ${ }^{\mathrm{m} C} \mathrm{C}-\mathrm{TdR}$ & $\begin{array}{l}\text { 5-methylcytidine } \\
\text { tritiated thymidine }\end{array}$ \\
\hline TT & tetanus toxoid & APC & antigen presenting cell \\
\hline
\end{tabular}

\section{INTRODUCTION}

Human T lymphocytes derive from precursors in the bone marrow, which migrate as prothymocytes to the thymus. In the thymus, these cells interact with products of the major histocompatibility complex (MHC) plus thymic hormones, and in response to these signals, differentiate into $T$ cells [1-5]. During maturation, the thymocytes express a series of cell surface molecules identified by monoclonal antibodies. Stage $\mathrm{I}$ thymocytes are $\mathrm{T} 11^{+} \mathrm{T} 6^{-} \mathrm{T} 4^{-} \mathrm{T} 8^{--} \mathrm{T} 3^{--}$, while stage II

From the Department of Internal Medicine, University of Michigan, Ann Arbor, Michigan.

Address reprint requests to Bruce Richardson, Department of Internal Medicine University of Michigan, Ann Arbor, MI 48109.

Received April 16, 1986; accepted June 26, 1986. 
thymocytes are $\mathrm{T} 11^{+} \mathrm{T} 6^{+} \mathrm{T} 4^{+} \mathrm{T} 8^{+} \mathrm{T} 3^{-}$and stage III thymocytes are $\mathrm{T} 11^{+}$ $\mathrm{T}^{-} \mathrm{T}^{+}{ }^{+} \mathrm{T} 8^{-} \mathrm{T} 3^{+}$or $\mathrm{T} 11^{+} \mathrm{T} 6^{-} \mathrm{T} 4^{-} \mathrm{T} 8^{+} \mathrm{T} 3^{+}[6,7]$. The T-cell receptor, associated with $\mathrm{T} 3$, appears only on the surface of stage III thymocytes [7]. During this process, a majority of the thymocytes proliferate, apparently in response to self class II MHC gene products without antigen, and more than $60 \%$ of thymocytes die in the thymus $[1,3,8]$. In contrast to thymocytes, the mature $T$ cell entering the peripheral circulation must recognize antigen in addition to self $\mathrm{MHC}$ products to proliferate.

Selective activation and suppression of gene expression presumably mediates the phenotypic and functional changes observed in maturing thymocytes. One mechanism governing gene transcription is DNA methylation. In many systems, unmethylated DNA sequences can be shown to correlate with gene expression, while methylated sequences are transcriptionally inactive [9-16]. In particular, hypomethylation of regulatory sequences $5^{\prime}$ to the structural sequences appear to correlate with active transcription of the structural sequences $[9,12,14]$.

5-azacytidine (5-azaC) is a nucleoside analog that alters DNA methylation. 5azaC, when added to proliferating cells, prevents methylation of newly synthesized DNA by inhibiting DNA (cytosine-5-)-methyltransferase, an enzyme that methylates cytidine in $\mathrm{CpG}$ sequences on the daughter DNA strand when ${ }^{\mathrm{m}} \mathrm{CpG}$ is identified in the parent DNA strand [17,18]. Cells treated with 5-azaC express new functional and histologic features when DNA methylation is inhibited $[15,19-23]$. Thus, $5-a z a C$ is a convenient tool to induce expression of genes suppressed by DNA methylation.

To test whether DNA methylation may be involved in the phenotypic functional changes observed during thymic maturation, we treated cloned, antigenspecific Interleukin-2 (IL-2) dependent $\mathrm{T}^{+}{ }^{+}$and $\mathrm{T}^{+}$human $\mathrm{T}$-cell lines with 5 azaC. In this report, we demonstrate that antigen-specific $\mathrm{T}^{+}{ }^{+}$cells, when treated with 5-azaC, proliferate to autologous class II MHC determinants analogous to the less mature thymocyte. No changes in the phenotype of the mature $\mathrm{T}^{+}$ cells were observed.

\section{MATERIALS AND METHODS}

Isolation of peripheral blood mononuclear cells (PBMCs). Heparinized peripheral venous blood obtained from normal volunteers was centrifuged at $300 \times \mathrm{g}$ for $10 \mathrm{~min}$ at room temperature; the buffy coat aspirated, and PBMCs separated by density gradient centrifugation on Ficoll-Paque (Pharmacia, Piscataway, NJ) according to the method of Boyum [24]. PBMCs were stored frozen in liquid nitrogen, and thawed according to the method of Donaldson et al. [25]. Viability of the thawed cells is usually $>97 \%$ by trypan blue exclusion.

Purification of adberent cells. Adherent cells were isolated by allowing PBMCs to bind to $60 \times 15 \mathrm{~mm}$ plastic petrie dishes (Falcon \#1007, Oxnard, CA) for 45 min in RPMI 1640 (GIBCO, Grand Island, NY) containing 10\% human AB serum. Nonadherent cells were rinsed off with RPMI 1640, and adherent cells were removed by adding $5 \mathrm{ml}$ of RPMI $1640 / 10 \%$ AB serum $/ 24 \mathrm{mM}$ lidocaine for $15 \mathrm{~min}$ at room temperature, followed by three washes with RPMI at $4^{\circ} \mathrm{C}$. This population is referred to as macrophages $(M \varnothing)$.

$I L$-2-dependent $T$-cell lines. A volunteer was boosted with tetanus toxoid. Fourteen or more days later, PBMCs were isolated and cultured in round bottomed 96well microtiter plates (Nunc, from GIBCO Laboratories, Grand Island, NY) in 
RPMI 1640 containing $10 \%$ AB serum, $100 \mathrm{U} / \mathrm{ml}$ penicillin, $100 \mu \mathrm{g} / \mathrm{ml}$ streptomycin, and nonalum absorbed tetanus toxoid (TT) (Wyeth, Marietta, PA) at a final dilution of 1:50. Cultures were maintained at $37^{\circ} \mathrm{C}$ in a humidified incubator in an atmosphere of $5 \% \mathrm{CO}_{2}$. After 4 days the cells were transferred into complete medium containing RPMI $1640,20 \%$ AB serum, penicillin, streptomycin, and 20\% IL-2 (supernatant from the MLA-144 cell line) [26]. After several doublings of total cell numbers, the $T$ cells were cloned by limiting dilution at 0.2 cells/well into flat bottomed microtiter wells (Nunc) containing $10^{5}$ mitomycin-C treated or irradiated (2000 R) autologous PBMCs, complete medium, and TT. Cloned lines were maintained in 24 well plates (Nunc) by weekly rechallenge with $10^{6}$ irradiated $(2000 \mathrm{R}$ ) or mitomycin-C inactivated $\mathrm{PBMC} /$ well plus TT, and twice weekly addition of fresh complete medium.

Phenotype of cloned T-cell lines. T-cell phenotype was determined using the OKT4 (Ortho Pharmaceuticals, Raritan, NJ) and Leu-2 (Becton-Dickinson, Mountain View, CA) monoclonal antibodies. Cells stained with fluorescein isothiocyanate (FITC) and phycoerythrin (PE) conjugated antibodies were analyzed with a Coulter EPICS V or C flow cytometer, using a modification of the procedures previously described $[27,28]$.

Proliferation assay. T-cell proliferation assays were performed by washing IL-2 dependent T cells free of IL-2, then culturing $2 \times 10^{3}$ to $10^{4} \mathrm{~T}$ cells with graded numbers of mitomycin- $C$ treated or irradiated $(2000 \mathrm{R}) \mathrm{M} \varnothing$ in media containing RPMI $1640,10 \%$ AB serum, $100 \mathrm{U} / \mathrm{ml}$ penicillin, and $100 \mu \mathrm{g} / \mathrm{ml}$ streptomycin. The cells were cultured in round-bottomed 96 well microtiter plates in a total volume of 200 microliters per well. Antigen was added at varying concentrations. In some experiments, $20 \mu \mathrm{l}$ of IL-2 containing supernatant was added to each well on day 3, and $5 \mu \mathrm{Ci}$ tritiated thymidine $\left({ }^{3} \mathrm{H}-\mathrm{TdR}\right.$ ) (New England Nuclear, Boston, MA) was added to each well on day 5 . Sixteen hours later, the cells were harvested onto glass fiber filters with a Mini-MASH (Microbiological Associates, Walkersville, MD), dried, and radioactivity measured with a Packard 574 liquid scintillation spectrophotometer. Results are expressed as the mean of triplicate wells \pm SEM. In experiments using monoclonal antibodies to inhibit activation, the antibodies were used at a final concentration of $100 \mathrm{ng} / \mathrm{ml}$ with the exception of 1.41 , which was used at $1 \mathrm{ng} / \mathrm{ml}$.

Reagents and monoclonal antibody binding assay. 5-azacytidine, cycloheximide, sodium butyrate, actinomycin $\mathrm{D}$, and hydroxyurea (HU) were purchased from Sigma Chemical Corporation (St. Louis, MO). Candida albicans (C.alb.) was purchased from Hollister-Stier, Spokane, WA. Anti-T3, anti-T6, and anti-T4a antibodies wete purchased from Ortho Pharmaceuticals (Raritan, NJ) and anti-HLA A,B,C from Cappel Laboratories (Cochranville, PA). The $1.41 \mathrm{~B}$ cell hybrid secreting anti-HLA D framework antibody was a generous gift from Dr. $H$. McDevitt [29]. Monoclonal antibody concentration was determined by an ELISA technique [30,31] using class-specific antisera (Litton Bionetics, Kensington, MD) to coat 96 well plates (Nunc Immuno-Plate I, from GIBCO). Test samples or serial dilutions of known amounts of purified myeloma protein of the appropriate immunoglobulin class (Litton Bionetics) were allowed to bind to the coated wells. Horseradish peroxidase conjugated goat anti-mouse IgG (Sigma) was used to detect bound mouse immunoglobulin. The assay was developed with $\mathrm{O}$-dianisidine and color development was measured in a Titertek Multiskan (Flow Laboratories Inc., McLean, VA). Full details are provided elsewhere [31]. 


\section{RESULTS}

\section{5-azaC Treated, $\mathrm{T}^{+}{ }^{+}$Antigen Reactive $\mathrm{T}$ Cells Can Respond to $\mathrm{M} \varnothing$ Without Antigen}

Cloned Interleukin-2 (IL-2) dependent human T-cell lines were obtained by immunizing a volunteer with TT, in vitro stimulation of peripheral blood mononuclear cells with TT, and cloning by limiting dilution. Four cloned lines, TT 16E, TT18I, TT18M, and TT18X, were obtained which were $\mathrm{T}^{+}{ }^{+} \mathrm{T}^{-}{ }^{-}$as determined by flow cytometry. The reactivity of the lines with TT was tested by culturing the lines with mitomycin-C treated PBMCs and serial dilutions of TT. All four lines responded to TT in a dose-dependent fashion (Table 1), demonstrating that each line was TT reactive. TT16E did not react with C.alb., an unrelated antigen.

Thymocytes, in contrast to mature $\mathrm{T}$ cells, proliferate in response to autologous class II molecules in the absence of antigen $[1,3]$. To test whether 5 -azaC could induce these cloned, $\mathrm{T}_{4}{ }^{+}$antigen reactive cells to respond to class II MHC molecules alone, 5 -azacytidine $(0.25-4 \mu \mathrm{M})$ was added to subcultures of T"T18X. Four to 6 days after treatment the cells were washed and tested for reactivity to varying number of autologous $M \varnothing_{s}$ with and without antigen. The results are shown in Figure 1. The cloned $\mathrm{T}^{+}$antigen reactive $\mathrm{T}$-cell line, when treated with 5-azaC, acquired the ability to respond to autologous $M \emptyset$ s without antigen, while untreated cells required both antigen and macrophages. The optimal 5azaC concentration for TT18X was $1.0 \mu \mathrm{M}$; lower concentrations were ineffective, while higher concentrations proved toxic. For convenience, the 5-azaC induced proliferative response to $\mathbf{M} \emptyset$ without antigen will be referred to as "5-azaC induced self-reactivity."

The response of both untreated and 5-azaC treated TT18X to TT presented by $M \varnothing$ is less than the response observed when unfractionated PBMCs are used as antigen presenting cells (APC). This was observed for all cloned T-cell lines tested (see also Table 2), and may represent suppression by the $M \varnothing$ [32] or depletion of more potent antigen presenting cells [33]. However, the use of purified M $\varnothing$ s permits a more precise enumeration of HLA-D bearing APCs and minimizes the possibility that other cell populations, such as regulatory $\mathrm{T}$ cells, are responsible for or involved in the abnormal responses seen in 5-azaC treated cells. Furthermore, the use of purified $M \emptyset$ s allows us to tentatively identify the stimulating cell as the $M \varnothing$, although a response to a minor contaminating subpopulation cannot be excluded. For these reasons, all studies were performed

TABLE 1 Reactivity of cloned T-cell lines (Proliferation of cloned lines (CPM \pm SEM))

\begin{tabular}{|c|c|c|c|c|c|}
\hline Antigen & Dilution & TT16E $\mathrm{E}^{a}$ & $\operatorname{TT} 18 \mathrm{I}^{a}$ & $\mathrm{TT}^{*} 18 \mathrm{M}^{a}$ & $\mathrm{TT} 18 \mathrm{X}^{a}$ \\
\hline TT & $1: 4$ & $3,768+571$ & $2,854 \pm 12$ & $12,392 \pm 688$ & $10,431 \pm 3,051$ \\
\hline $\mathrm{TT}$ & $1: 8$ & $10,157 \pm 2,291$ & $4,251 \pm 1,655$ & $11,644 \pm 2,428$ & $12,665 \pm 1,251$ \\
\hline TT & $1: 16$ & $11,033 \pm 700$ & $9,163 \pm 2,576$ & $8,553 \pm 1,550$ & $10,762 \pm 480$ \\
\hline$T T$ & $1: 32$ & $\mathrm{nd}^{b}$ & $14,087 \pm 3,097$ & $2,846 \div 2,459$ & $4,456 \pm 2,115$ \\
\hline \multirow[t]{3}{*}{ c.alb } & $1: 6$ & $384 \pm 23$ & $\mathrm{nd}^{b}$ & $\mathrm{nd}^{b}$ & $n \mathrm{~d}^{b}$ \\
\hline & $1: 18$ & $1,366 \pm 520$ & & & \\
\hline & $1: 54$ & $893 \pm 179$ & & & \\
\hline None & & $832 \pm 179$ & $3,570 \pm 101$ & $218 \pm 193$ & $171 \pm 36$ \\
\hline
\end{tabular}

“ $10^{4}$ cloned T cells were cultured with $10^{5}$ mitomycin-C treated PBMCs in $0.2 \mathrm{ml}$ of RPMI $1640 / 10 \%$ AB serum plus antigen. Twenty milliliters of IL-2 containing supernatant was added on day 3 and proliferation measured on day 6 by ${ }^{3} \mathrm{H}-\mathrm{TdR}$ incorporation. Results are expressed as the mean \pm SEM of triplicate cultures.

${ }^{b}$ nd: not done. 


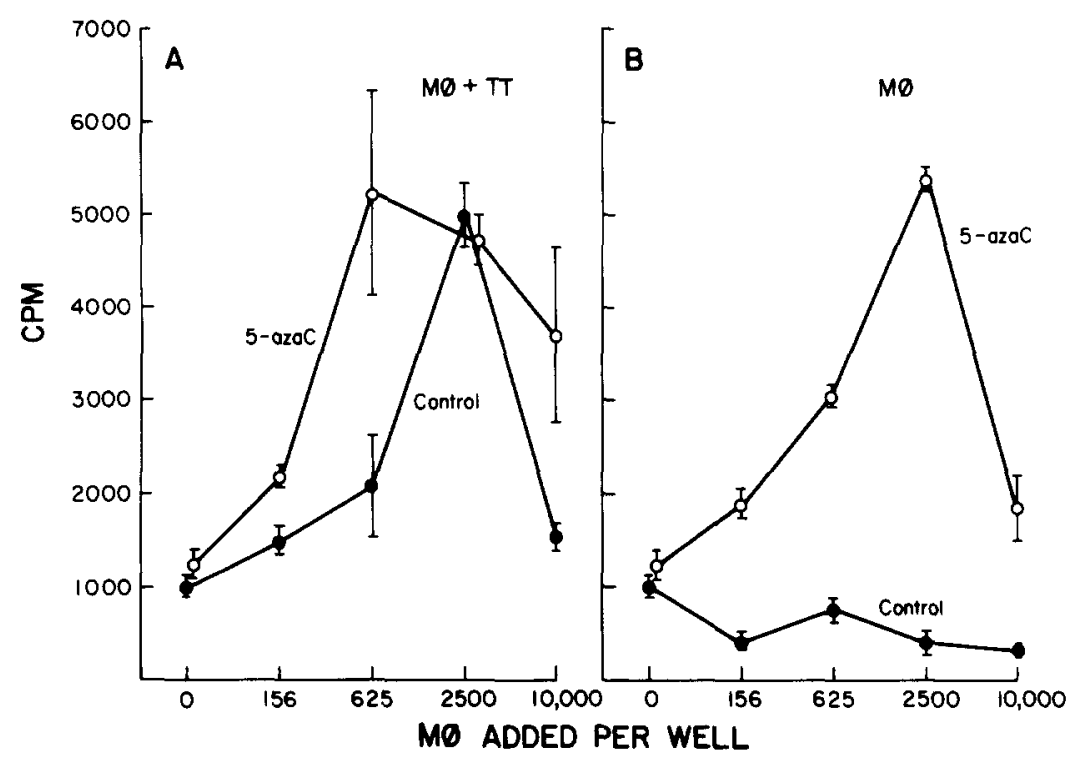

FIGURE 1 Cloned $T$ cells were treated with $1.0 \mu \mathrm{M} 5$-azaC and 6 days later $10^{4}$ treated and untreated cells were cultured with graded numbers of mitomycin-C treated $M \emptyset_{s}$ (156-10,000/well) with (A) or without (B) TT diluted 1:50. Twenty microliters of Interleukin- 2 were added on day 3 , and proliferation was measured on day 6 by incorporation of ${ }^{3} \mathrm{H}-\mathrm{TdR}$. The ordinate scale is the same in both panels.

with $M \emptyset_{\text {s rather than }}$ PBMCs, although the $M \varnothing_{\text {s frequently gave lower prolif- }}$ erative responses.

To test whether 5 -azaC induced self-reactivity was unique to the TT18X cloned line, the three other $\mathrm{T} 4{ }^{+}$TT reactive cloned lines were similarly treated with 5 $\mathrm{azaC}$, then challenged with autologous $M \varnothing$ with and without antigen. These experiments are summarized in Table 2. 5-azaC not only induces self-reactivity in TT18X, but in TT18I, TT16E, and TT18M as well. Of note is that both TT18I and TT18M required $1.0 \mu \mathrm{M} 5$-azaC while $0.5 \mu \mathrm{m}$ was most effective in TT16E (data not shown). This variability in optimal 5 -azaC concentration, although slight, was reproducible. In these studies the optimal T cell: M $\varnothing$ ratio for activating 5azaC treated $T$ cells was found to be $1: 1$, and this ratio was used in subsequent studies. When the results presented in Figure 1 and Table 2 are compared, it can be seen that in some experiments the proliferative response of 5-azaC treated cells to $M \varnothing$ plus TT was greater than the response to $M \varnothing$ alone, while in other experiments the opposite is true, and occasionally the responses are of equal magnitude (Figure 1). The relative magnitudes of the responses varied between experiments, even for the same line, and the reason is not clear. However, an explanation could be that only a fraction of 5-azaC treated cells change phenotype [15], resulting in fewer cells responding to $M \emptyset$ without TT. Moreover, the resulting two populations may express different growth rates, resulting in changes in the relative proportions of the phenotypes. The $M \varnothing$ responsive phenotype was routinely stable for at least 2 weeks. After this time, variable results were obtained, and for this reason, subsequent studies were performed 4-14 days after 5 -azaC treatment. To test whether the variability observed over time was due to instability of the 5 -azaC induced changes or to more rapid growth of cells activated by both $M \emptyset$ and antigen, attempts were made to grow the 5-azaC treated cells 
TABLE 25 -azaC causes antigen reactive cells to proliferate to $\mathrm{M} \varnothing$ without antigen

\begin{tabular}{lcccc}
\hline T cells $^{\alpha}$ & Treatment $^{b}$ & M & TT $^{c}$ & CPM \pm SEM $^{d}$ \\
\hline TT18M & - & - & - & $1,241 \pm 133$ \\
TT18M & - & + & - & $777 \pm 125$ \\
TT18M & - & + & + & $2,181 \pm 39$ \\
TT18M & 5 -azaC & - & - & $791 \pm 27$ \\
TT18M & 5-azaC & + & - & $13,968 \pm 1,932$ \\
TT18M & 5-azaC & + & + & $6,343 \pm 712$ \\
TT18I & - & - & - & $916 \pm 76$ \\
TT18I & - & + & - & $226 \pm 46$ \\
TT18I & - & + & + & $3,003 \pm 328$ \\
TT18I & 5 -azaC & - & - & $336 \pm 3$ \\
TT18I & 5 -azaC & + & - & $4,002 \pm 283$ \\
TT18I & 5 -azaC & + & + & $1,499 \pm 141$ \\
TT16E & - & - & - & $558 \pm 51$ \\
TT16E & - & + & - & $95 \pm 20$ \\
TT16E & - & + & + & $1,332 \pm 125$ \\
TT16E & 5-azaC & - & - & $219 \pm 76$ \\
TT16E & 5 -azaC & + & + & $4,204 \pm 263$ \\
TT16E & 5-azaC & + &,$+ 467 \pm 396$ \\
\hline
\end{tabular}

${ }^{a} 10^{4} \mathrm{~T}$ cells were cultured with $10^{4}$ autologous mitomycin-C treated $\mathrm{M} \emptyset$, as described in Materials and Methods and Figure 1

${ }^{b}$ Cells were treated with an optimal concentration of 5 -azaC, and used in these experiments at least 6 days after treatment. TT181 and TT18M responded optimally when treated with $1.0 \mu \mathrm{M}$ 5-azaC, while TT16E required 0.5 $\mu \mathrm{M}$ 5-azaC.

'TT was used at a final concentration of 1:50.

${ }^{d}$ Results are expressed as the mean \pm SEM of triplicate cultures.

by repeated stimulation with PBMCs alone. These experiments failed to maintain the lines. Similarly, attempts to subclone the treated cells by limiting dilution onto PBMCs without TT also failed. These results suggest that the 5-azaC induced changes in T-cell reactivity are unstable. In other systems, 5-azaC induced changes may be stable, but clearly some are not [10], so these results remain consistant with the known effects of 5-azaC.

In summary, these results demonstrate that 5 -azaC induced self-reactivity is not unique to the TT18X cloned line, and that other $\mathrm{T}^{+}{ }^{+}$antigen-specific cloned lines display the same responses. In contrast, 5 -azaC induced self-reactivity was not observed in two $\mathrm{T}^{+}$, TT specific T-cell lines [34].

One potential explanation for the 5 -azaC induced self-reactivity is that 5 -azaC treated $\mathrm{T}$ cells may respond abnormally to the exogenous IL-2 used in the proliferation assay. To test for this, untreated and 5-azaC treated TT16E cells were cultured with equal numbers of autologous mitomycin-C treated $M \varnothing$, with and without TT, in the absence of IL-2 (Figure 2). As can be seen, 5-azaC induced self-reactivity was still observed, with a maximum proliferation on day 4 . Similar results were observed with TT18I (data not shown). In Figure 2, the magnitude of the proliferation induced by $M \emptyset$ alone was greater than that induced by $M \varnothing$ plus TT. This may reflect a change in the optimal number of $M \emptyset$ and optimal TT concentration necessary for T-cell activation following 5-azaC treatment, although other factors, such as more rapid growth of self-reactive cells relative to nontransformed cells, cannot be excluded. Since 5-azaC induced self-reactivity was still observed despite withholding exogenous IL-2, the exogenous IL-2 prep- 

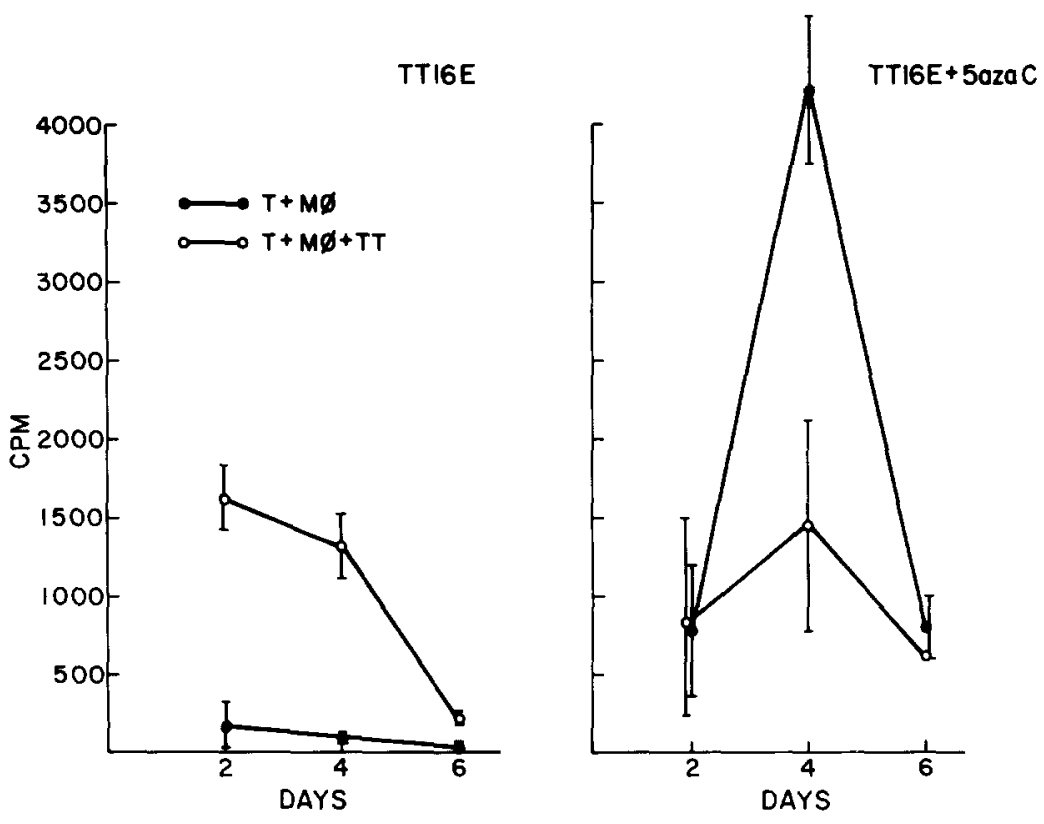

FIGURE 2 Exogenous IL-2 is not required for 5 -azaC induced autoreactivity. $10^{4}$ untreated TT16E (left panel) or $10^{4} \mathrm{TT} 16 \mathrm{E}$ treated with $0.5 \mu \mathrm{M} 5$-azaC (right panel) were cultured with an equal number of mitomycin-C treated $M \emptyset$, or with $10^{4}$ autologous $M \emptyset$ plus TT at 1:50 final dilution. Proliferation was measured on days 2, 4, and 6 by ${ }^{3} \mathrm{H}-\mathrm{TdR}$ uptake. Each point represents the mean \pm SEM of triplicate cultures. Controls containing T cells cultured alone gave background proliferations of $552 \pm 21$ CPM for TT16E and $695 \pm 394$ for TT16E treated with $0.5 \mu \mathrm{M} 5$-azaC (mean \pm SEM of the three time points). The ordinate scale is the same in both panels.

aration cannot be responsible for the proliferation observed. However, because exogenous IL-2 often augmented proliferative responses, subsequent assays were performed using added IL-2.

In many systems, 5-azaC has been demonstrated to induce gene expression by inhibiting DNA methylation [9-16]. However, some authors report that 5azaC can also induce gene expression through an undefined toxic effect on certain cell types [35]. To determine whether the self-reactivity induced by 5 -azaC is due to inhibition of DNA methylation or another mechanism such as inhibition of DNA synthesis, TT18I was treated with 5-azaC or hydroxyurea (HU) for 4 days, then washed and tested for self-reactivity as before. HU is an inhibitor of DNA synthesis which does not affect DNA methylation $[36,37]$, but which has been demonstrated to induce hemoglobin $\mathrm{F}$ synthesis in bone marrow cultures [35]. Cells treated with $12.5 \mu \mathrm{M}$ HU, the highest concentration tested which does not kill IL-2 dependent $T$ cells, failed to induce self-reactivity, while 1.0 $\mu \mathrm{M} 5$-azaC induced $\mathrm{M} \varnothing$ reactivity (Table 3). Lower concentrations of $\mathrm{HU}$ also failed to induce $\mathrm{M} \varnothing$ reactivity (data not shown). This indicates that 5 -azaC induces $M \varnothing$ reactivity through mechanisms other than inhibition of DNA synthesis.

\section{5-azaC Treated $\mathrm{T}^{+}$Cells Respond to Class II MHC Determinants on $\mathbf{M} \varnothing$}

To determine whether 5 -azaC treated $\mathrm{T} 4{ }^{+} \mathrm{T}$ cells are activated by class II MHC determinants on $M \emptyset$, analogous to thymocytes, monoclonal antibodies to frame- 
TABLE $3 \quad 5$-azaC but not hydroxyurea causes $\mathrm{T}^{+}$antigen reactive $\mathrm{T}$ cells to proliferate to $M \varnothing$ without antigen ${ }^{a}$

\begin{tabular}{llcccc}
\hline Cells & Treatment & M $\varnothing$ & TT & $\begin{array}{c}\text { Exp. I } \\
\text { CPM } \pm \text { SEM }\end{array}$ & $\begin{array}{c}\text { Exp. II } \\
\text { CPM } \pm \text { SEM }\end{array}$ \\
\hline TT18I & 5-azaC & - & - & $1,154 \pm 64$ & $2,819 \pm 558$ \\
TT18I & $5-a z a C$ & + & - & $16,125 \pm 1,777$ & $8,046 \pm 321$ \\
TT18I & 5-azaC & + & + & $20,467 \pm 2,112$ & $13,332 \pm 2,146$ \\
TT18I & HU & - & - & $2,224 \pm 558$ & $803 \pm 232$ \\
TT18I & HU & + & - & $3,496 \pm 741$ & $1,407 \pm 79$ \\
TT18I & HU & + & + & $9,927 \pm 85$ & $28,111 \pm 1,299$ \\
\hline
\end{tabular}

${ }^{a} \mathrm{~T}$ cells were treated with $1.0 \mu \mathrm{M} 5$-azaC or $12.5 \mu \mathrm{M} \mathrm{HU}$ and 4 days later used for these studies. $10^{4}$ treated $\mathrm{T}$ cells were cultured with equal numbers of miromycin-C treated autologous $M \emptyset$, and TT was used at a dilution of 1:50. IL-2 was added on day 3 and proliferation measured on day 6 by ${ }^{3} \mathrm{H}-\mathrm{TdR}$ incorporation.

work determinants on class I or class II MHC gene products were used to inhibit activation of cloned $T$ cells by irradiated autologous $M \varnothing$ (Table 4). As can be seen, monoclonal antibodies binding to framework determinants on HLA-A, $-B$, and $-C$ molecules had no effect on activation of the $T$ cells, while antibody to HLA-D molecules inhibited $\mathrm{T}$-cell activation, suggesting that the $\mathrm{T}$ cells are recognizing and activated by class II MHC determinants on the $M \varnothing$. To further support this observation, studies were performed using allogeneic M $\varnothing$ s. Table 5 shows experiments in which 5 -azaC treated TT specific $\mathrm{T}^{+}{ }^{+} \mathrm{T}$ cells were cultured with autologous or allogeneic irradiated $M \emptyset_{\text {s. Autologous }} \mathrm{M} \emptyset_{\mathrm{s}}$ activated the $T$ cells, while allogeneic $M \varnothing$ s did not, indicating that the $T$ cells recognize determinants unique to the autologous $M \varnothing$, such as $M H C$ determinants. Taken together, the inhibition of T-cell activation by an HLA-D specific monoclonal antibody and the failure of allogeneic $M \emptyset_{s}$ to activate the $\mathrm{T}$ cells strongly suggests that the 5 -azaC treated $\mathrm{T}$ cells are activated by the polymorphic determinants of self class II MHC molecules alone.

\section{Anti-T3 Antibodies Inhibit Activation of 5-azaC Treated T Cells}

To test whether the T3-Ti complex was involved in class II antigen induced proliferation, 5-azaC treated $\mathrm{TT}$ specific $\mathrm{T} 4^{+}$cells were again activated by autologous $M \varnothing$ s, and monoclonal antibodies to the T3 and class I MHC molecules were used to inhibit the activation. Table 6 demonstrates that anti-T 3 monoclonals

TABLE 4 Monoclonal antibodies to HLA-D molecules inhibit activation of 5-azaC treated $T 4^{+} T$ cells by macrophages without antigen ${ }^{a}$

\begin{tabular}{lccccc}
\hline Cells & MØ & Antibody & $\begin{array}{c}\text { Exp. I } \\
\text { CPM } \pm \text { SEM }\end{array}$ & $\begin{array}{c}\text { Exp. II } \\
\text { CPM } \pm \text { SEM }\end{array}$ & $\begin{array}{c}\text { Exp. III } \\
\text { CPM } \pm \text { SEM }\end{array}$ \\
\hline TT18I & - & - & $1,345 \pm 107$ & $2,633 \pm 697$ & $710 \pm 103$ \\
TT181 & + & - & $5,020 \pm 705$ & $6,860 \pm 520$ & $3,423 \pm 590$ \\
TT18I & + & anti-HLA A,B,C & $5,070 \pm 766$ & $6,727 \pm 556$ & $4,211 \pm 1,438$ \\
TT18I & + & anti-HLA D & $2,952 \pm 809$ & $3,198 \pm 596$ & $1,077 \pm 573$ \\
\hline
\end{tabular}

${ }^{a} 10^{4} \mathrm{~T}$ cells and $10^{4} \mathrm{M} \emptyset$ were cultured as described in Table 1. IL-2 was added on day 3 and proliferation measured on day 6 by ${ }^{3} \mathrm{H}-\mathrm{TdR}$ incorporation. No antigen was added. Monoclonal antibody concentration were $100 \mathrm{ng} / \mathrm{ml}$ for anti-HLAA,-B,-C, and $1 \mathrm{ng} / \mathrm{ml}$ for anti-HLA-D. 
TABLE 5 Allogeneic macrophages do not activate 5-azaC treated TT18I ${ }^{a}$

\begin{tabular}{ccc}
\hline & Exp. I & Exp. II \\
M $\varnothing$ DR type & CPM \pm SEM & CPM \pm SEM \\
\hline$\overline{-}^{b}$ & $233 \pm 87$ & $2,286 \pm 309$ \\
$4,4^{c}$ & $7,362 \pm 158$ & $6,024 \pm 360$ \\
$1,-d$ & $1,505 \pm 197$ & $2,357 \pm 819$ \\
$4,-d$ & $784 \pm 96$ & $3,027 \pm 853$ \\
3,5 & $439 \pm 166$ & $\mathrm{nd}^{d}$ \\
\hline
\end{tabular}

${ }^{a} 10^{4}$ TT18I cells were cultured with $10^{4} \mathrm{M} \emptyset$ as described in Table 1 . No antigen was added.

${ }^{b}$ No $M \emptyset$ added.

'Autologous $\mathrm{M} \emptyset$ are 4,4.

${ }^{a}$ Parents not typed.

end = not done.

inhibited this activation, while anti-HLA-A, -B, -C monoclonal antibodies did not. In these studies, aggregated anti-T3 antibody was removed by centrifugation at $100,000 \times \mathrm{g}$ and exogenous IL-2 was not added to the assay. Under these conditions, the OKT 3 antibody blocked activation, rather than directly activating the cells. In other studies, anti-T4a monoclonal antibodies at $100 \mathrm{ng} / \mathrm{ml}$ failed to inhibit activation (data not shown). These data suggest that the activation of antigen specific $\mathrm{T}$ cells by class II MHC molecules alone involves the T3-Ti complex [38-42]. One possible explanation for this observation is that 5-azaC induces a quantitative change in the amount of the T3-Ti complex on the cells. To test for this, $\mathrm{T} 3$ expression of treated and untreated cells was compared using flow cytometry. No significant quantitative change in $\mathrm{T} 3$ was induced on the cells, and light scatter measurements showed the size of the treated and untreated cells was similar (data not shown). This suggests that a quantitative change in the amount of surface $\mathrm{T} 3$ is not responsible for the self-reactivity.

TABLE 6 OKT3 inhibits activation of 5 -azaC treated $\mathrm{T}^{+}{ }^{+}$cells by macrophages without antigen ${ }^{a}$

\begin{tabular}{ccccr}
\hline Experiments & Cells & MØ & Antibody & CPM \pm SEM \\
\hline 1 & TT18I & - & - & $710 \pm 59$ \\
& TT18I & + & - & $2,288 \pm 39$ \\
& TT18I & + & anti-HLA A,B,C & $2,804 \pm 639$ \\
& TT18I & + & OKT3 & $598 \pm 107$ \\
2 & TT16E & - & - & $626 \pm 435$ \\
& TT16E & + & - & $3,059 \pm 370$ \\
& TT16E & + & anti-HLA A,B,C & $2,092 \pm 169$ \\
& TT16E & + & OKT3 & $848 \pm 438$ \\
3 & TT18I & - & OKT3 & $832 \pm 148$ \\
& TT18I & + & anti-HLA A,B,C & $3,469 \pm 471$ \\
& TT18I & + & OKT3 & $842+232$ \\
\hline
\end{tabular}

${ }^{\circ} \mathrm{T}^{+}{ }^{+}$cloned $\mathrm{T}$-cell lines were treated with $0.5-1.0 \mu \mathrm{M} \mathrm{S-azaC}$ as before. $\mathrm{T}$ cells were cultured as described in Table 1, except that no exogenous IL-2 was added and proliferation measured on day 5. Cell density was $10^{4} \mathrm{~T}$ cells and $10^{4} \mathrm{M} \emptyset /$ well. Monoclonal antibodies were used at $100 \mathrm{ng} / \mathrm{ml}$. OKT3 was centrifuged at $100,000 \times \mathrm{g}$ for $15 \mathrm{~min}$ immediately prior to use. 


\section{The Surface Phenotype of 5-azaC Treated T4 ${ }^{+}$Cells Does Not Change}

$T$ cells maturing in the thymus also express a defined series of surface molecules identified by monoclonal antibodies. The Common, or stage II thymocyte, expresses the phenotype $\mathrm{T} 6^{+} \mathrm{T} 4^{+} \mathrm{T} 8^{+} \mathrm{T} 3^{-}$. Mature thymocytes and $\mathrm{T}$ cells are either $\mathrm{T} 6^{-} \mathrm{T}^{+}{ }^{+} \mathrm{T} 8^{-} \mathrm{T} 3^{+}$or $\mathrm{T} 6^{-} \mathrm{T} 4^{-} \mathrm{T}^{+} \mathrm{T} 3^{+}[6,7]$. To test whether surface phenotype was also changed by 5 -azaC treatment, T4, T6, and $\mathrm{T} 8$ expression were evaluated by flow cytometry before and after 5 -azaC treatment. The 5-azaC treated cells remained $\mathrm{T} 4^{+}{ }^{+} 8^{-}$, and total $\mathrm{T} 4$ expression was not changed (data not shown). Similarly, T6 was not induced. In contrast, 5-azaC can be shown to induce $\mathrm{T} 4$ expression on $\mathrm{T} 8^{+}$cells [34]. In some systems, sodium butyrate acts synergistically with 5 -azaC to induce gene expression, via a mechanism involving both DNA methylation and histone acetylation [16,43-46]. Accordingly, 5-azaC treated $\mathrm{T}_{4}{ }^{+}$cells were treated with $1-10 \mathrm{mM}$ sodium butyrate. No detectable T8 was induced. These results demonstrate that expression of the T8 determinant is either not regulated by methylation, or that additional mechanisms beyond DNA methylation regulate these molecules.

\section{DISCUSSION}

The data presented in this report demonstrate that cloned, $\mathrm{T}_{4}^{+}$antigen reactive human $\mathrm{T}$-cell lines treated with 5-azaC, but not hydroxyurea, can be activated by autologous $M \emptyset_{\mathrm{s}}$ in the absence of antigen. The observations that monoclonal antibodies to HLA-D determinants inhibit this activation, and that allogeneic $M \varnothing$ s fail to activate the cells, indicate that the treated $T$ cells are recognizing class II MHC gene products on the M $\varnothing$. The observation that $\mathrm{M} \emptyset$ from a second DR4 donor did not activate 5 -azaC treated $\mathrm{T}$ cells may be due to the $\mathrm{T}$ cell identifying $\mathrm{D}$ region products not identified by currently available typing sera and unique to the T-cell donor. The most likely interpretation of these observations is that 5 -azaC induces expression of as yet unidentified genes involved in thymocyte activation but suppressed by mechanisms involving DNA methylation in mature $\mathrm{T}$ cells. 5 -azacytidine has been demonstrated to induce gene expression in other systems by inhibiting methylation of newly synthesized DNA [9-16,47]. For example, 5-azaC has been used to change the metastatic growth characteristics of tumor cells [19], change fibroblasts and undifferentiated embryo cells into adipocytes, chondrocytes and muscle cells $[15,20]$, induce IL-2 production in nonsecreting thymoma cells [21], induce the macrophage-like properties of phagocytosis, cytoplasmic granules, and vacuoles in B-lymphocyte cell lines [22], and transform myoblasts into myofibers [23]. Many of these transformations are unstable, although some are not [10]. Therefore, the observation that the 5-azaC induced self-reactivity became unstable after 2 weeks is still consistant with the described effects of 5-azaC. 5-azaC has other effects on cellular metabolism, such as inhibition of DNA synthesis [48], and can induce expression of certain genes presumably via these mechanisms. It is unlikely that this nonspecific effect is responsible for the changes induced in $\mathrm{T}^{+}{ }^{+} \mathrm{T}$ cells, since hydroxyurea, an inhibitor of DNA synthesis which does not affect DNA methylation, does not induce $M \varnothing$ reactivity. This observation suggests that 5 -azaC is acting via inhibition of methylation $[36,37,47]$. Experiments testing this hypothesis are underway.

The hypothesis that 5 -azaC induces gene(s) which enable $T$ cells to respond to class II MHC antigens alone is consistant with thymocyte responses observed during $\mathrm{T}$-cell maturation. During maturation, thymocytes are induced to proliferate, apparently by class II MHC determinants alone $[1,3]$, but mature $\mathrm{T}$ cells 
must bind both MHC molecules and antigen for activation to occur. Methylation of crucial genes may occur during thymic maturation resulting in the requirement for mature $\mathrm{T}$ cells to identify both antigen and class II molecules for activation.

One candidate for a gene that could alter $T$-cell specificity, and which is suppressed during the maturation of $\mathrm{T} 4^{+}$cells, is the $\gamma$ chain of the $\mathrm{T}$-cell receptor. This gene is initially coexpressed with the $\beta$ chain gene in immature thymocytes. Cells that ultimately become $\mathrm{T} 4{ }^{+}$suppress $\gamma$ chain expression and activate the $\alpha$ chain gene [49,50]. The $\gamma \beta$ receptor, on T cells destined to become $\mathrm{T} 4^{+}$, may recognize autologous class II $\mathrm{MHC}$ molecules with sufficient avidity to activate the cell, committing it to the $\mathrm{T}^{+}{ }^{+}$lineage. Suppression of the $\gamma$ chain could serve to decrease the receptor affinity, allowing HLA-D recognition through the $\beta$ chain, but with too low avidity for activation to occur. A necessary corollary of this hypothesis would be that the $\alpha$ chain serves as the antigen recognition unit. If the $\alpha$ chain also recognized HLA-D molecules with sufficient avidity to activate the cell as an $\alpha \beta$ receptor, the cell would have to be eliminated, rather than be released from the thymus. Experiments testing $\gamma$ chain expression in 5 azaC treated $\mathrm{T}^{+}$cells are underway.

A second, but less likely, explanation for the reactivity changes induced by 5 $\mathrm{azaC}$ is that all four cloned lines tested may contain a subset of $\mathrm{T}$ cells that respond to class II molecules alone or in conjunction with some unidentified molecule(s) present in the tissue culture system. Such reactivity is referred to as the autologous mixed lymphocyte reaction, or AMLR [51-55], and is also inhibited by anti-class II monoclonal antibodies and anti-T3 antibodies [56]. This subset would have to be consistantly selected for by 5-azaC to explain these observations. Moreover, the induction of self-reactivity by 5 -azaC has been observed in four out of four lines tested. Finally, self-reactivity has not been observed among these cells without 5-azaC treatment. For these reasons it is unlikely that the observed effects are due to a contaminating AMLR responsive T-cell subpopulation among the TT reactive cells.

The observation that anti-T3 antibodies inhibit activation of the 5 -azaC treated T cells by class II MHC molecules alone is interesting. The T3 family of molecules are noncovalently attached subunits of the clonally distributed $\mathrm{T}$-cell receptor $[38,40]$. Antibodies to this complex inhibit antigen reactivity, alloreactivity, and AMLR reactivity $[38,39,56,57]$, implicating this receptor in the recognition of antigenic determinants and/or class II MHC determinants. Since 5-azaC treated cloned TT reactive $\mathrm{T}$ cells are activated by class II MHC determinants without TT, the inhibition by anti-T3 antibodies implies that this receptor complex is involved in recognition of class II MHC molecules. A second possibility is that anti-T3 antibodies may deliver an inhibitory signal to the $\mathrm{T}$ cell, preventing activation of the cell through a separate $\mathrm{MHC}$ receptor. This possibility is difficult to evaluate at this time, as this receptor would need to be independent of the T3 molecules. Quantitative changes in the expression of the T3-Ti complex could also potentially alter the activation requirements for the cells. However, this latter mechanism is unlikely as total $\mathrm{T} 3$ expression could not be shown to change with 5-azaC treatment.

Antigen-specific murine T-T hybrids have also been activated by class II determinants alone $[58,59]$. One reason that hybrids, but not normal antigen reactive $\mathrm{T}$ cells can be activated by $\mathrm{MHC}$ products alone, may be related to the abnormal genetic regulation of malignant cells and their hybrids. Moreover, activation in these systems is measured by lymphokine secretion, as the cells are already proliferating, and regulation of lymphokine secretion may differ from proliferation.

The relationship of AMLR reactive $T$ cells and 5-azaC treated antigen reactive 
T cells is unknown. The AMLR may represent normal antigen-specific $T$ cells with crucial genes activated which allow it to respond to self class II molecules alone, analogous to 5 -azaC treated cells. An alternative view is that the AMLR represents $T$ cells activated by undefined antigens present in tissue culture systems

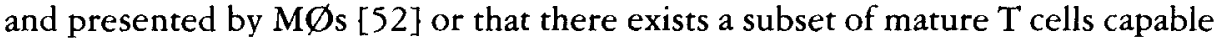
of responding to self $\mathrm{MHC}$ products alone [51,54] possibly involved in immune regulation $[54,60,61]$. These possibilities may be sorted out if genes activated by 5 -azaC can be identified and their expression tested in AMLR reactive cells.

A final point of interest is that the induction of $T$-cell reactivity to class II MHC molecules alone by 5 -azaC represents induction of autoreactivity in a normal $\mathrm{T}$ cell. This observation suggests that normal $\mathrm{T}$ cells can be made autoreactive by chemicals or other agents, possibly viruses, which activate genes responsible for self-reactivity. Such cells could play a role in autoimmune diseases.

\section{ACKNOW/LEDGMENTS}

The author thanks Ms. P. Graham and Ms. J. Spicker for expert technical assistance, and Ms. C. Sercel for secretarial assistance. Special thanks is given to Dr. H. McDevitt for his generous gift of the 1.41 monoclonal antibody, to Drs. B.M. Peterlin and J.D. Stobo for helpful discussions, and to Dr. Joel Depper for reviewing this manuscript.

This work was supported by USPHS grants PGO AM-20557-07 and 1 R23 AI2145401 .

\section{REFERENCES}

1. Kyewski BA, Travis $M$, Kaplan $H$ : Intrathymic lymphopoiesis: stromal cell-associated proliferation of T cells is independent of lymphocyte genotype. J Immunol 133:1111, 1984.

2. Wu S, Thomas DW: Thymocyte and macrophage interactions: separation of murine thymocyte subsets and entichment of syngeneic cell-responding thymocytes by absorption to macrophage monolayers. J Immunol 131:2110, 1983.

3. Rock KL, Benacerraf B: Thymic $T$ cells are driven to expand upon interaction with self-class II major histocompatibility complex gene products on accessory cells. Proc Natl Acad Sci 81:1221, 1984.

4. Low TLK, Goldstein AL: Thymosins: structure, function and therapeutic applications. Thymus 6:27, 1984.

5. Pahwa R, Ikehara S, Pahwa SG, Good RA: Thymic function in man. Thymus 1:27, 1979.

6. Reinherz EL, Schlossman SF: The differentiation and function of human T lymphocytes. Cell 19:821, 1980.

7. Royer HD, Acuto $\mathrm{O}$, Fabbi $M$ et al.: Genes encoding the Ti $\beta$ subunit of the antigen/MHC receptor undergo rearrangement during intrathymic ontogeny prior to surface T3-Ti expression. Cell 39:261, 1984.

8. McPhee D, Pye J, Shortman K: The differentiation of T lymphocytes. V. Evidence for intrathymic death of most thymocytes. Thymus 1:151, 1979.

9. Busslinger M, Hurst J, Flavell RA: DNA methylation and the regulation of globin gene expression. Cell 34:197, 1983.

10. Ley TJ, Chiang YL, Haidaris D et al.: DNA methylation and regulation of the human $\beta$-globin like genes in mouse erythroleukemia cells containing human chromosome 11. Proc Natl Acad Sci USA 81:6618, 1984. 
11. Storb U, Arp B: Methylation patterns of immunoglobulin genes in lymphoid cells: correlation of expression and differentiation with undermethylation. Proc Natl Acad Sci USA 80:6642, 1983.

12. Jost J-P, Seldran M, Geiser M: Preferential binding of estrogen-receptor complex to a region containing the estrogen-dependent hypomethylation site preceding the chicken vitallogenin II gene. Proc Natl Acad Sci USA 81:429, 1984.

13. Mavilio F, Giampaolo A, Care et al.: Molecular mechanism of human hemoglobin switching: selective undermethylation and expression of globin genes in embryonic, fetal, and adult erythroblasts. Proc Natl Acad Sci USA 80:6907, 1983.

14. Langener K-D, Vardimon L, Renz D, Doerfler W: DNA methylation of three 5' CC-G-G 3 ' sites in the promoter and $5^{\prime}$ region inactivate the $\mathbf{E} 2 \mathrm{a}$ gene of adenovirus type 2. Proc Natl Acad Sci USA 81:2950, 1984.

15. Jones PA, Taylor SM: Cellular differentiation, cytidine analogs and DNA methylation. Cell 20:85, 1980.

16. Ginder GD, Whitters MJ, Pholman: Activation of a chicken embryonic globin gene in adult erythroid cells by 5-azacytidine and sodium butyrate. Proc Natl Acad Sci USA 81:3954, 1984.

17. Stein R, Gruenbaum Y, Pollack Y et al.: Clonal inheritance of the pattern of DNA methylation in mouse cells by 5 -azacytidine and sodium butyrate. Proc Natl Acad Sci USA 81:3954, 1982.

18. Santi DV, Norment A, Garrett CE: Covalent bond formation between a DNAcytosine methyltransferase and DNA containing 5-azacytosine. Proc Natl Acad Sci USA 81:6993, 1984.

19. Olsson L, Forchhaammer J: Induction of the metastatic phenotype in a mouse tumor model by 5 -azacytidine, and characterization of an antigen associated with metastatic activity. Proc Natl Acad Sci USA 81:3389, 1984.

20. Taylor SM, Jones PA: Multiple new phenotypes induced in $10 \mathrm{~T} 1 / 2$ and $3 \mathrm{~T} 3$ cells treated with S-azacytidine. Cell 17:771, 1979.

21. Ballas $\mathrm{ZK}$ : The use of 5 -azacytidine to establish constitutive interleukin-2 producing clones of the EL4 thymoma. J Immunol 133:7, 1984.

22. Boyd AW, Schrader JW: Deriviation of macrophage-like lines from the pre-B lymphoma ABLS 8.1 using 5-azacytidine. Nature 297:692, 1982.

23. Scarpa S, Strom R, Bozzi A et al.: Differentiation of myoblast cell lines and biological methylation: 3-deazaadenosine stimulates formation of multinucleated myofibers. Proc Natl Acad Sci USA 81:3964, 1984.

24. Boyum A: Isolation of lymphocytes, granulocytes and macrophages. Scand J Immunol 5(Suppl 5):9, 1976.

25. Donaldson SL, Miller GA, Rice PL, Ranney RR, Tew JG: The maintenance of B-cell and T-cell function in frozen and stored human lymphocytes. J Clin Immunol 1:106, 1981.

26. Rabin H, Hopkins RF, III, Ruscetti FW et al.: Spontaneous release of a factor with properties of $\mathrm{T}$ cell growth factor from a continuous line of primate tumor $\mathrm{T}$ cells. J Immunol 127:1852, 1981.

27. Pandolfino E: New standard for cellular immunology. Am Clin Prod Rev 1984.

28. Loke MR, Lanier LL: New standard for cellular immunology. Am Clin Prod Rev 1984.

29. Charron DJ, McDevitt HO: Characterization of HLA-D-region antigens by two dimensional gel electrophoresis. Molecular genotyping. J Exp Med 152:185, 1980. 
30. Freidman SM, Principato MA, Thompson GS, Teichman F: Antigen-specific and polyclonal immunoglobulin production induced by a cloned tetanus toxoid-specific and polyclonal immunoglobulin production induced by a cloned tetanus toxoid-specific T cell line. J Immunol 130:1164, 1983.

31. Basic ELISA Procedure. Boehringer Mannheim Biochemicals Technical Services Department, 1981.

32. Rice L, Laughter AH, Twomey JJ: Three suppressor systems in human blood that modulate lymphoproliferation. J Immunol 122:991, 1979.

33. Voorhis WCV, Valiusky J, Hoffman E, Luban J, Hair LS, Steinman RM: Relative efficacy of human monocytes and dendritic cells as accessory cells for $T$ cell replication. J Exp Med 158:174, 1983.

34. Richardson B, Kahn L, Lovett EJ, Hudson J: Effect of an inhibitor of DNA methylation on $\mathrm{T}$ cells. I. 5-azacytidine induces $\mathrm{T} 4$ expession on $\mathrm{T} 8+\mathrm{T}$ cells. $\mathrm{J}$ Immunol, in press.

35. Letvin NL, Linch DC, Beardsley GP, McIntyre KW, Nathan DG: Augmentation of fetal-hemoglobin production in anemic monkeys by hydroxyurea. $\mathrm{N}$ Engl J Med 310:869, 1984.

36. Goehm TLJ, Kreis W, Drahovsky D: Inhibition of thymidylate synthase by hydroxyurea in rapidly proliferating P815 mastocytoma cells. Biochem Biophys Acta 696:52, 1982.

37. Radford IR, Martin RF, Finch LR: Effects of hydroxyurea on DNA synthesis in mouse L-cells. Biochem Biophys Acta 696:145, 1982.

38. Meure SC, Acuto O, Hussey RE, Hodgdon DC, Fitzgerald KA, Schlossman SF, Reinherz EC: Evidence for the T3 associated $90 \mathrm{~K}$ heterodimer as the $\mathrm{T}$-cell antigen receptor. Nature 303:808, 1983.

39. Meuer SC, Cooper DA, Hodgdon JC, Hussey RE, Fitzgerald KA, Schlossman SF, Reinherz EC: Identification of the receptor for antigen and major histocompatibility complex on human inducer T lymphocytes. Science 222:1239, 1983.

40. Meuer SC, Fitzgerald KA, Hussey RE, Hodgdon JC, Schlossman SF, Reinherz EC: Clonotypic structures involved in antigen-specific human $T$ cell function. Relationship to the T3 molecular complex. J Exp Med 157:705, 1983.

41. Marrack P, Shimokevitz R, Hanuum C, Harkins K, Kappler J: The major histocompatibility complex-restricted antigen and I-specificity. J Exp Med 158:1635, 1983.

42. Haskins K, Kubo R, White J, Pigeon M, Kappler J, Marrack P: The major histocompatibility complex-restricted antigen receptor on T cells. I. Isolation with a monoclonal antibody. J Exp Med 157:1449, 1983.

43. Leshin M: 5 -azacytidine and sodium butyrate induce expression of aromatase in fibroblasts from chickens carrying the henny feathering trait but not from wild-type chickens. Proc Natl Acad Sci USA 82:3005, 1985.

44. Kruh F: Effects of sodium butyrate, a new pharmacological agent, on cells in culture. Mol Cell Biochem 42:65, 1982.

45. Jahangeer S, Elliott RM, Henneberry RC: C3-adrenergic receptor inducton on HeLa cells: synergistic effect of 5-azacytidine and butyrate. Biochem Biophys Res Comm 108:1434, 1982.

46. Prasad KN: Butyric acid: a small fatty acid with diverse biological functions. Life Sci 27:1531, 1980.

47. Hones PA: Altering gene expression with 5-azacytidine. Cell 40:485, 1985.

48. Cihak A: Biological effects of 5-azacytidine in eukaryotes. Oncology 30:405, 1974. 
49. Geilig JS, Glimcher LH, Kranz DM, Clayton LK et al.: Expression of the T-cellspecific $\gamma$ gene is unnecessary in T cells recognizing class II MHC determinants. Nature 317:68, 1985.

50. Roulet DH, Garman RD, Saito H, Tanagawa S: Developmental regulation of the T cell receptor gene expression. Nature 314:103, 1985.

51. Weksler ME, Moody CE, Kozak RW: The autologous mixed-lymphocyte reaction. Adv Immunol 31:271, 1981.

52. Glimcher LH, Longo DL, Green I, Schwartz RH: Murine syngeneic mixed lymphocyte response. I. Target antigens are self Ia molecules. J Exp Med 154:1652, 1981.

53. Dos Reis GA, Shevach EM: The syngeneic mixed leukocyte reaction represents polyclonal activation of antigen-specific $\mathrm{T}$ lymphocytes with receptors for self Ia antigens. J Immunol 127:2456, 1981.

54. Hausman PB, Stobo JD: Specificity and function of a human autologous reactive T cell. J Exp Med 149:1537, 1979.

55. Huber C, Merkenschlager M, Gattringer C, Royston I, Fink U, Braunsteiner H: Human autologous mixed lymphocyte reactivity is primarily specific for xenoprotein determinants absorbed to antigen-presenting cells during rosette formation with sheep erthrocytes. J Exp Med 155:1222, 1982.

56. Romain PL, Schlossman SF, Reinherg EL: Surface molecules involved in self-recognition and $\mathrm{T}$ cell activation in the autologous mixed lymphocyte reaction. J Immunol 133:1093, 1984.

57. Acuto O, Reinherz EL: The human T-cell receptor. Structure and function. New Eng J Med 313:1100, 1985.

58. Glimcher LH, Schevach EM: Production of autoreactive I region-restricted T cell hybridomas. J Exp Med 156:640, 1982.

59. Rock KL, Benacerraf $\mathrm{B}$ : The role of la molecules in the activation of T lymphocytes. III. Antigen-specific, Ia-restricted Interleukin-2 producting $\mathrm{T}$ cell hybridomas with detectable affinity for the restricting I-A molecule. J Exp Med 157:359, 1983.

60. Sakane T, Green I: Specificity and suppressor function of human T cells responsive to autologous non-T Cells. J Immunol 123:584, 1979.

61. James SP, Yenokida GG, Groeff AS, Elson CO, Strober W: Immunoregulatory function of $\mathrm{T}$ cells activated in the autologous mixed lymphocyte reaction. $\mathrm{J}$ Immunol 127:2605, 1981. 